\title{
On the effects of search attributes on price variability: An empirical investigation on quality wines
}

\author{
Antonio Seccia ${ }^{1}$, Domenico Carlucci ${ }^{2}$, Fabio Gaetano Santeramo ${ }^{1}$, Tiziana Sarnari ${ }^{3}$, and Gianluca Nardone ${ }^{1}$ \\ ${ }^{1}$ Department of Agricultural, Food and Environmental Sciences, University of Foggia, Foggia, Italy \\ ${ }^{2}$ Department of Agro-Environmental and Territorial Sciences, University of Bari, Bari, Italy \\ ${ }^{3}$ Ismea, Roma, Italy
}

\begin{abstract}
The choice of a bottle of wine is affected by the presence of attributes that are searched by consumers and can be evaluated before the purchase. The aim of the paper is to analyze the effect of some search attributes on wine price variability applying the Hedonic Price Model. It allows explaining how the price of wine varies depending on its main quality attributes. The analysis has been based on a sample of wines made in Puglia, Italian region characterized by a tradition in wine production and consumption. Data have been collected from a wine guidebook considering the years 2008-2013. The study provided a measure of the market value of some search attributes for wines produced in Puglia. Attributes as alcoholic content, age and score given by experts, influence price variability allowing wines to obtain a premium price, such as the most known Protected Designation of Origin (PDO) and some Protected Geographical Indication (PGI). The name of the variety seems not to have high influence with the exception of less known and locally grown varieties. Results may be of interest for marketers and policy makers of wine industry. Managerial implications could refer to the importance of differentiation strategies aimed to market segmentation and to the pricing strategy. Policymakers could also find interesting hints about the influence of the different appellations and the importance of minor autochthonous grape varieties.
\end{abstract}

\section{Introduction}

Wine is a highly differentiated product made from grapes of different varieties grown under various pedoclimatic conditions which change a lot across geographical areas and years. This wide heterogeneity is reflected on the wine price that, such as for other products, is associated with the quality as perceived by consumers. However, in most cases, purchasers compare different bottles of wine with no past consumption experience and so without really knowing the characteristics of the product. Consequently, a relevant role in the choice process is played by attributes whose presence can be verified before the purchase, known as "search attributes", reading the label on the bottle and looking for wine's description and evaluation, referred to a rating system, provided by experts.

The aim of this work is to analyze and quantify the effects that search attributes of wine such as color, alcoholic content, variety, age, area of production and sensory characteristics, can have on price. For this purpose, a "hedonic price model" has been estimated. This model relates the price of a generic good to its quality attributes. The concept is that any product embodies a bundle of characteristics that define its quality. The price of each attribute is implicit but the sum of implicit prices of all attributes determines the whole price of the product. Statistical analysis helps to measure consumers' evaluations of the different product attributes.

The analysis has been conducted on a sample of wines produced in Puglia, which is the third largest wine producing region in Italy, with an average production of more than 6 million hectolitres, equal to almost $13 \%$ of the national production, from a vineyard surface area of almost 86,000 hectares. Nearly $19 \%$ is certified as Protected Geographical Indication (PGI), whereas the incidence of wines with Protected Designation of Origin (PDO) is 4\% and the remaining production (77\%) is referred to table wine [1]. In Puglia, there are 32 wines with PDO and 6 wines with PGI. Red wines from autochthonous varieties (Primitivo, Negramaro and Nero di Troia) are the main exported products and the primary export market is Europe (Germany, Austria, the Netherlands and Denmark) but the most profitable market is United States (6-7\% of the total export by value from the region). Export share towards Canada and Japan is increasing, whereas Apulian wine is still less known in new consumers countries as Brazil, Russia, India and China.

This study aims to contribute to a better understanding of the influence of search attributes on wine price by using an approach that takes into account both the demand and supply sides. This kind of analysis has important practical implications related to the possibility of quantifying the individual effect of each quality attribute on the overall price of wine. In fact, as Oczkowski [2] pointed out, if the benefit associated with a particular quality attribute (implicit price) could be compared with the relative costs incurred, producers could make better strategic choices. Thus, the results of this study may be useful in understanding the evolutionary dynamics of Apulian wine market and in addressing marketing strategies as companies face an expanding market that is also characterized by increasing competitive pressure and rapidly changing consumer preferences. Moreover, results could be useful to policymakers for decisions regarding 
the effectiveness of appellations as Protected Designation of Origin (PDO) and Protected Geographical Indication (PGI) and the relevance that minor autochthonous grape varieties have in characterizing the identity of a territory.

The remainder of this paper is organized as follows: Sect. 2 briefly presents an overview of the literature about hedonic price with a focus on wine; Sect. 3 gives a detailed description of the applied methodology; Sect. 4 discusses the results; Sect. 5 summarizes the main findings and highlights some implications.

\section{Literature review}

According to Lancaster's theory of demand [3], the utility that a consumer can derive from a product depends on the characteristics embedded in it and, under the assumption of perfect competition, the theory suggests that consumers' willingness to pay depends on the bundle of several quality attributes that are independently valued by consumers at the time of purchase. So, the observed market price of a product is the sum of implicit prices paid for each quality attribute [4]; implicit prices can be estimated by employing a hedonic price model which is a regression model capable of expressing the observable price of any particular product as a function of its characteristics (directly or indirectly observable). This theoretical model is based on the assumption of a general economic equilibrium in a perfectly competitive market; therefore, consumers maximize utility by choosing available products under budget constraints and firms maximize profits given the available technology and factor prices [4]. As a consequence, being related to both supply and demand conditions, implicit prices cannot be considered merely as indicators of consumer preferences $[2,4,5]$. Moreover, in a situation in which there is imperfect competition, implicit prices are also affected by the choices of producers who take into account their own market power, price elasticity of demand for each attribute, and the costs required to incorporate each attribute in the final product [6].

In literature, a large number of studies have adopted this approach for analysis applied to the market of wine because this product is characterized by high degree of differentiation associated with price variability more than other food products $[7,8]$. For estimating implicit prices, many authors have focused on some wine characteristics that consumers evaluate when making a purchasing decision: the importance of the area of production $[5,9,10]$, the reputation of the winery [11,12], grape varieties [9,13-15], colour [16] and sensory quality ratings $[8,9,17]$. In addition, this approach has been adopted to assess the influence in pricing structure of product packaging characteristics [18], different price segments [17] and retail formats [19].

The estimation of a hedonic price function deals with some methodological issues. First, a sufficiently large sample size is needed to conduct the estimate and, regarding that, in previous works, wine guidebooks have been used as source of data [2,5,9,20-23]. Further, a crucial aspect is the choice of wine attributes to include in the function as regressors, which is influenced by both data availability and specific objectives of the analysis. Generally, attributes directly valued by consumers before purchasing wine are considered the most suitable for this methodology: colour, alcohol content, area of origin (country, region, sub-region), vintage, variety. Many works have considered such attributes which have shown high significance [2, 5, 7,9, 14,20-27]. In addition, some authors have proved that, other characteristics being equal, brand and certification of origin play a significant role on the price variability $[5,9,20,21,23]$. Finally, a hedonic price function should include a variable referred to the sensory characteristics of wine. In fact, a positive judgement by consumers on a wine quality will probably lead to repeat purchases and to attract new customers with the result of a price increase. However, it is not easy to find one or more variables that objectively measure the organoleptic quality of a wine. Such issue has been taken into account considering a scoring system for the evaluation of wines by a panel of experts. Some authors have found that scores reported in wine guides do have a significant impact on prices, stating that wine experts judges, playing a role as opinion leaders, have a heavy influence on consumers, mainly when choosing premium wines $[2,5,9,20]$. On the other hand, other authors have observed a low significance of experts' scores and tried to explain such result with the high degree of subjectivity in wine sensory evaluation that could not reflect preferences of consumers [7,21-23].

The present paper contributes to the existing literature focusing on wines produced in a specific region, the third for production in Italy, and using an approach that considers prices suggested by wineries, as dependent variable, and information readable on the label, as independent variables, so taking into account both the demand and supply sides.

\section{Methodology}

\subsection{Hedonic price model}

In this study a hedonic price equation has been estimated with the aim of analyzing the relationship between the price and the main search attributes of wine. Almost every considered attribute can be easily recognized by consumers at the time of purchase by reading label information, particularly, alcoholic content, vintage, colour, area of production (as designation of origin and geographical indication) and variety. Since the price of a wine also largely depends on its organoleptic characteristics, as shown in previous researches $[2,5,9,20]$, it has been considered appropriate to include, as an attribute, the evaluation of the sensory characteristics of the wine made by a panel of experts.

\subsection{Data collection and data-set}

Data were collected from the annual wine guidebook "Guida dei Vini di Puglia" published by the newspaper "La Gazzetta del Mezzogiorno" considering the editions of 6 years from 2008 to 2013. This guide includes more than 150 wineries located in Puglia region, reporting, for each of them, a description of three wines: the most expensive, the winemaker choice and a new product. The description provides information readable on the label as well as the suggested retail price (Euro/bottle 0.75 liter) and a rating (ranging from 1 to 4 stars) based on the organoleptic evaluation provided by a team of experts from the Italian Sommelier Association (AIS), the Italian Association of Oenologists and the National Wine Tester Organization (ONAV). The number of only three wines 
Table 1. Characteristics of the Sample (Price in Euro/bottle 0.75lt).

\begin{tabular}{|c|c|c|c|c|c|}
\hline & Number & Min Price & Max Price & Average Price & St. Dev. \\
\hline & 2280 & 1,90 & 80,00 & 10,57 & 6,80 \\
\hline \multicolumn{6}{|c|}{ Alcohol content } \\
\hline$<12$ & 51 & 2,46 & 16,20 & 5,83 & 2,81 \\
\hline $12-12,9^{\circ}$ & 464 & 2,30 & 25,00 & 6,89 & 2,52 \\
\hline $13-13,9^{\circ}$ & 1022 & 1,90 & 42,00 & 9,68 & 4,80 \\
\hline $14-14,9^{\circ}$ & 593 & 3,50 & 55,00 & 13,03 & 7,12 \\
\hline $15-15,9^{\circ}$ & 106 & 5,00 & 78,00 & 16,92 & 9,43 \\
\hline$>16^{\circ}$ & 44 & 4,50 & 80,00 & 26,90 & 16,17 \\
\hline \multicolumn{6}{|c|}{ Age } \\
\hline 1 year & 915 & 2,46 & 35,00 & 7,70 & 3,42 \\
\hline 2 years & 608 & 2,30 & 45,00 & 10,83 & 6,10 \\
\hline 3 years & 407 & 1,90 & 80,00 & 13,30 & 8,48 \\
\hline 4 years & 208 & 4,00 & 52,00 & 13,30 & 6,52 \\
\hline 5 years & 84 & 5,50 & 43,50 & 13,13 & 6,93 \\
\hline 6 years & 36 & 6,00 & 50,00 & 17,61 & 10,52 \\
\hline$>6$ years & 22 & 5,50 & 78,00 & 24,93 & 18,45 \\
\hline \multicolumn{6}{|c|}{ Colour } \\
\hline Red & 1514 & 1,90 & 80,00 & 12,01 & 7,62 \\
\hline White & 463 & 2,50 & 25,00 & 8,02 & 3,52 \\
\hline Rosè & 303 & 2,46 & 25,00 & 7,29 & 2,85 \\
\hline \multicolumn{6}{|c|}{ Score } \\
\hline 1 star & 286 & 1,90 & 25,00 & 7,70 & 3,37 \\
\hline 2 stars & 1024 & 2,46 & 42,00 & 9,17 & 4,51 \\
\hline 3 stars & 843 & 3,00 & 80,00 & 11,85 & 7,56 \\
\hline 4 stars & 127 & 4,00 & 75,00 & 19,80 & 11,42 \\
\hline \multicolumn{6}{|c|}{ Appellation of Origin } \\
\hline PGI & 1539 & 2,3 & 78 & 9,31 & 5 \\
\hline PDO & 741 & 1,9 & 80 & 10,29 & 5,45 \\
\hline \multicolumn{6}{|c|}{ Protected Geographical Indication } \\
\hline Salento & 882 & 2,50 & 78,00 & 11,07 & 7,25 \\
\hline Puglia & 501 & 2,30 & 30,00 & 9,53 & 5,08 \\
\hline Daunia & 64 & 3,50 & 20,00 & 8,54 & 4,58 \\
\hline Tarantino & 34 & 3,00 & 20,00 & 9,27 & 4,07 \\
\hline Murgia & 31 & 3,00 & 18,00 & 8,27 & 3,32 \\
\hline Valle d'Itria & 27 & 4,50 & 35,00 & 9,19 & 5,68 \\
\hline \multicolumn{6}{|c|}{ Protected Designation of Origin } \\
\hline Primitivo & 151 & 3,50 & 48,00 & 13,41 & 6,68 \\
\hline Salice Salentino & 145 & 4,20 & 35,00 & 10,17 & 5,42 \\
\hline Castel del Monte & 119 & 2,46 & 55,00 & 11,67 & 9,00 \\
\hline Gioia del Colle & 81 & 5,00 & 80,00 & 14,93 & 12,28 \\
\hline Brindisi & 36 & 1,90 & 16,00 & 7,59 & 3,11 \\
\hline Copertino & 33 & 4,80 & 35,00 & 8,84 & 5,34 \\
\hline Locorotondo & 26 & 4,00 & 14,00 & 6,97 & 2,31 \\
\hline San Severo & 19 & 3,00 & 10,00 & 5,60 & 2,45 \\
\hline Moscato di Trani & 17 & 5,00 & 16,00 & 11,97 & 3,15 \\
\hline Others PDOs & 114 & 3,25 & 35,00 & 10,66 & 5,27 \\
\hline \multicolumn{6}{|c|}{ Variety } \\
\hline Blend of Varieties & 730 & 1,90 & 78,00 & 10,50 & 6,14 \\
\hline Single varietal & 1550 & 2,46 & 80,00 & 10,84 & 7,06 \\
\hline Primitivo & 516 & 3,00 & 80,00 & 12,91 & 8,13 \\
\hline Negroamaro & 376 & 3,00 & 52,00 & 9,91 & 6,63 \\
\hline Other National & 287 & 2,46 & 30,00 & 8,44 & 3,99 \\
\hline Minor local & 263 & 3,00 & 55,00 & 11,79 & 7,44 \\
\hline International & 108 & 3,00 & 22,50 & 7,76 & 4,10 \\
\hline
\end{tabular}

for each winery could represent a limit for the sample but the considered guidebook is the most comprehensive for the Apulian wineries. The collected data-set contains 2280 observations coming from 6 editions of the guidebook. The data-set has been considered as cross-section under the hypothesis that prices are not affected by inflation.
A preliminary analysis of the data-set has been carried out by calculating descriptive statistics - such as the number of cases, minimum, maximum, average and standard deviation of price - regarding both the total sample and specific sub-samples distinguished according to a particular quality attribute (Table 1 ). 
In the sample, wines' great price variability is noteworthy, ranging from a minimum of 1.90 Euro/bottle to a maximum of 80.0 Euro/bottle with an average of 10.57 Euro/bottle.

According to the alcohol content $(\% \mathrm{~V} / \mathrm{V}), 6$ subsamples have been derived (less than $12^{\circ} ; 12^{\circ}-12.9^{\circ}$; $13^{\circ}-13.9^{\circ} ; 14^{\circ}-14.9^{\circ} ; 15-15.9^{\circ} ; 16^{\circ}$ or more $)$. It is interesting to note that the average price of the wines included in each subsample regularly increases as the alcohol content increases. In fact, it is 5.83 Euro/bottle for wines with alcohol content of less than $12^{\circ}$ while it is 26.90 Euro/bottle for wines with alcohol content higher than $16^{\circ}$.

The influence of age on the price of wine is showed considering the increasing trend of the average price in the 7 subsamples distinguished by the age of wine; it ranges from 7.70 Euro/bottle for the first group to 24.93 Euro/bottle for the group of wines of more than 6 years.

Considering the colour, the average price of red wines is higher than white and rosé (12.01 Euro/bottle compared respectively to 8.02 and 7.29 Euro/bottle); however, standard deviation of red wines is much higher showing greater price variability.

The prices of wines also show a fairly clear relationship with the score assigned by experts in accordance with the sensory characteristics. In fact, the average price of wines that have received the minimum score of one star is 7.7 Euro/bottle, rising to 9.17 Euro/bottle for those in the next group, to 11.85 Euro/bottle for those of the three stars group, and, finally, reaching 19.8 Euro/bottle in the top group.

In the sample, there are 741 wines with the appellation of origin PDO (Protected Designation of Origin) and 1539 with the appellation of origin PGI (Protected Geographical Indication). The difference between the average prices of the two groups is quite less than expected: in the former group is 10.29 Euro/bottle whereas for the latter is 9.31 Euro/bottle; however, the standard deviation for PDOs reveals higher price variability. With reference to the PGI appellations, 6 subsamples have been derived reflecting the number of PGIs in Puglia which are: Salento, Puglia, Daunia, Tarantino, Murgia, and Valle d'Itria. Salento and Puglia concentrate almost 90\% of the PGIs observations, with the former accounting for more than $57 \%$, and showing the highest average prices (11.7 and 9.53 Euro/bottle respectively). Wines with PDO appellations have been split up into 10 subsamples considering the frequency of observations in the group: Primitivo di Manduria, Salice Salentino, Castel del Monte, Gioia del Colle, Brindisi, Copertino, Locorotondo, San Severo, Moscato di Trani, Other PDOs. Primitivo di Manduria has the highest number of observations among PDOs, 151 cases corresponding to 20\%, followed by Salice Salentino, Castel del Monte, Gioia del Colle and Brindisi. The average price, not considering the group other PDOs, ranges from 5.6 Euro/bottle for San Severo to 14.9 Euro/bottle for Gioia del Colle, which shows a great price variability.

The sample includes $1550(68 \%)$ wines made from single varietal grapes and $730(32 \%)$ from varietal blends (using two or more grape varieties). In the first group, the most observed varieties are Primitivo with 516 cases (23\%) and Negramaro with 376 cases (16,5\%) which are autochthonous of Puglia and among the 20 most widespread cultivars in Italy. They are followed by wines from varieties widespread in Italy (Montepulciano, Sangiovese, Falanghina, Malvasia, Moscato, etc.), from other Apulian autochthonous varieties (Nero di Troia, Fiano Minutolo, Bombino Bianco, Primitivo di Gioia, Bombino Nero, Verdeca, Aglianico, etc.) and from international varieties (Chardonnay, Merlot, Cabernet Sauvignon, Sauvignon, Sirah, etc.). Price comparison shows a small difference in the maximum price between blends and varietal wines, 80 Euro/bottle for the latter and 78 Euro/bottle for the former.

\subsection{Empirical model}

Information included in the above-described data-set has been used for the specification of the following hedonic price equation:

$$
\begin{array}{r}
\text { InPrice }=\alpha+\beta \text { Alcoholic_content }+\gamma \text { Age }+\delta \text { Score } \\
+\eta_{i} \text { Colour }_{i}+\theta_{n} \text { Variety }_{n}+\lambda_{j} \text { Appellation }_{j}+\varepsilon .
\end{array}
$$

The variables included in the empirical model are listed and briefly described in Table 2 .

The price of the bottle has been used as dependent variable (Price) in the empirical hedonic price equation, and it is a continuous variable ranging from the lowest value 1.9 Euro/bottle to the maximum 80.0 Euro/bottle. Three explanatory variables, alcoholic content (Alcoholic_content), age (Age) and score (Score) are continuous variables as well, while the other explanatory variables, being categorical, have been entered as dummy variables. Alcoholic content (Alcoholic_content) ranges from the minimum of $10.5^{\circ}$ to the maximum of $19.0^{\circ}$ with an average of $13.4^{\circ}$; age (Age) ranges from 1 year to 14 years with a medium age of 2 ; score (Score) is referred to the evaluation of experts who have ranked wines using a scale from 1 to 4 stars.

The remaining explicative variables, being categorical, have been transformed into groups of dichotomous variables or dummies. The colour (Colour) has been coded as 3 dummy variables: red, white and rosé; the first has been considered as the baseline variable. The appellation of origin (Appellation) has coded as 16 dummy variables: 6 for each Apulian PGI, 9 for each of the most common Apulian PDOs and 1 for the remaining PDOs which have been considered together as a baseline dummy variable. Finally, 6 dummy variables have been considered for Variety: the first and the second are referred to wines produced from the main Apulian varieties, Negramaro and Primitivo; the third to wines made from other autochthonous grapes (Nero di Troia, Sussumaniello, Ottavianello, Verdeca, Bombino Nero, Aleatico, Bianco di Alessano, Fiano, Greco, etc.); the fourth to wines from national varieties (Montepulciano, Malvasia Bianca, Moscato, ecc.); the fifth to wines from international varieties (Chardonnay, Merlot, Cabernet Sauvignon, Sauvignon, Sirah, Pinot Noir); the sixth to wines obtained by blended varieties which has been considered as the baseline variable. The justification to create three distinct groups for varietal wines from, respectively, minor autochthonous varieties, other national varieties and international varieties, each of them as 
Table 2. Variables of the Empirical Model.

\begin{tabular}{|c|c|c|}
\hline Variables & Tipology & Description \\
\hline \multicolumn{3}{|c|}{ Dependent variable } \\
\hline Price & Continuous variable & Price of wine expressed in Euro/bottle $0.75 \mathrm{lt}$ \\
\hline \multicolumn{3}{|l|}{ Regressors } \\
\hline Alcohol_content & Continuous variable & Alcohol content expressed in \% Vol \\
\hline Age & Continuous variable & Age of wine expressed in years \\
\hline Score & Continuous variable & Score expressed in number of stars \\
\hline \multirow[t]{4}{*}{ Colour } & Categorical variable & \\
\hline & Dummy & Red $=1$; otherwise $=0$ (baseline) \\
\hline & Dummy & White $=1 ;$ otherwise $=0$ \\
\hline & Dummy & Rosè $=1 ;$ otherwise $=0$ \\
\hline \multirow[t]{17}{*}{ Appellation } & Categorical variable & \\
\hline & Dummy & Other PDOs $=1 ;$ otherwise $=0$ (baseline) \\
\hline & Dummy & Salento $=1 ;$ otherwise $=0$ \\
\hline & Dummy & Puglia $=1 ;$ otherwise $=0$ \\
\hline & Dummy & Daunia $=1 ;$ otherwise $=0$ \\
\hline & Dummy & Tarantino $=1 ;$ otherwise $=0$ \\
\hline & Dummy & Murgia $=1 ;$ otherwise $=0$ \\
\hline & Dummy & Valle d'Itria $=1 ;$ otherwise $=0$ \\
\hline & Dummy & Primitivo di Manduria $=1 ;$ otherwise $=0$ \\
\hline & Dummy & Salice Salentino $=1 ;$ otherwise $=0$ \\
\hline & Dummy & Castel del Monte $=1 ;$ otherwise $=0$ \\
\hline & Dummy & Gioia del Colle $=1 ;$ otherwise $=0$ \\
\hline & Dummy & Brindisi $=1 ;$ otherwise $=0$ \\
\hline & Dummy & Copertino $=1 ;$ otherwise $=0$ \\
\hline & Dummy & Locorotondo $=1 ;$ otherwise $=0$ \\
\hline & Dummy & San Severo $=1 ;$ otherwise $=0$ \\
\hline & Dummy & Moscato di Trani $=1 ;$ otherwise $=0$ \\
\hline \multirow[t]{7}{*}{ Variety } & Categorical variable & \\
\hline & Dummy & Blend $=1 ;$ otherwise $=0$ (baseline $)$ \\
\hline & Dummy & Primitivo $=1 ;$ otherwise $=0$ \\
\hline & Dummy & Negramaro $=1 ;$ otherwise $=0$ \\
\hline & Dummy & Other National $=1$; otherwise $=0$ \\
\hline & Dummy & Minor Autochtonous $=1 ;$ otherwise $=0$ \\
\hline & Dummy & International $=1 ;$ otherwise $=0$ \\
\hline
\end{tabular}

categorical variable, lies in the fact that the number of observations for each single variety in the sample is too small to provide a sufficiently robust estimation.

Finally, regarding the functional form of the equation, the literature does not clearly suggest among linear, semi-logarithmic and logarithmic forms. Nevertheless, for this work a semi-logarithmic functional form has been chosen, taking into account the easy interpretation of its coefficients and its flexibility.

\section{Results}

Estimation results of the hedonic price Equation using the method of Ordinary Least Square (OLS) are summarized in Table 3, which also includes the most important performance indicators of the empirical model. In particular, it is relevant to highlight a good overall significance (F-statistic equal to 61.01 with a P-value lower than 0.01 ) and a good capability to explain the variability of the data-set (adjusted R-squared equal to 0.56). It is possible to observe that the three continuous explicative variables have high statistical significance, even if with different magnitude of the coefficients.

The first, Alcohol_content has a coefficient equal to 0.24 . Taking into account the log-linear regression model, the coefficient of a continuous variable such as alcoholic content, explains the percentage change in price due to a unit variance of the explicative variable, all other characteristics being equal. So, one point increase in alcoholic content of wine is worth about $+24.0 \%$ in its price.

The variable Score, referred to the number of stars assigned to the wines by experts for the organoleptic characteristics, is significant as well. As a continuous variable, the regression outcome means that wines earn a $13 \%$ premium per unit of score, all other characteristics being equal.

Results show high correlation between price and the third continuous variable, Age, whose coefficient is 0.1 explaining that, as expected, wine aging has a positive effect on wine pricing, in this case the increase is $10 \%$ per year.

Considering the first of the three categorical variables, Colour, only the dummy referred to white wines is statistically significant. Since in the adopted model the coefficient of a dichotomous explanatory variable expresses the percentage change in price due to the presence of a given quality attribute (all other characteristics being equal), it follows that white wines show a difference of $6 \%$ in prices compared to red wines used as baseline. 
Table 3. Estimation Results.

\begin{tabular}{|c|c|c|c|c|c|}
\hline Variable & Coefficient & StandardError & TStatistic & PValue & Significance \\
\hline Costant & $-1,8079$ & 0,1782 & $-10,1411$ & $<0,0001$ & $* * *$ \\
\hline Alcoholic Content & 0,2458 & 0,0135 & 18,1368 & $<0,0001$ & $* * *$ \\
\hline \multicolumn{6}{|l|}{ Colour } \\
\hline Rosè & 0,0092 & 0,0274 & 0,3358 & 0,737 & \\
\hline White & 0,0666 & 0,0303 & 2,1975 & 0,0281 & $* *$ \\
\hline Score & 0,1349 & 0,0111 & 12,1226 & $<0,0001$ & $* * *$ \\
\hline Age & 0,1026 & 0,0078 & 13,001 & $<0,0001$ & $* * *$ \\
\hline \multicolumn{6}{|l|}{ Variety } \\
\hline Primitivo & $-0,1016$ & 0,0316 & $-3,2136$ & 0,0013 & $* * *$ \\
\hline Negroamaro & $-0,0272$ & 0,0248 & $-1,0947$ & 0,2737 & \\
\hline International & $-0,1313$ & 0,0441 & $-2,9763$ & 0,0029 & $* * *$ \\
\hline Minor autochtonous & 0,1565 & 0,0315 & 4,9582 & $<0,0001$ & $* * *$ \\
\hline Others national & $-0,0049$ & 0,0287 & $-0,1715$ & 0,8638 & \\
\hline \multicolumn{6}{|l|}{ Appellation of Origin } \\
\hline Salento-PGI & 0,221 & 0,0478 & 4,6186 & $<0,0001$ & $* * *$ \\
\hline Puglia-PGI & 0,2106 & 0,0499 & 4,2206 & $<0,0001$ & $* * *$ \\
\hline Daunia-PGI & 0,1753 & 0,072 & 2,4325 & 0,0151 & $* *$ \\
\hline Valle d'Itria-PGI & 0,2942 & 0,082 & 3,5885 & 0,0003 & $* * *$ \\
\hline Primitivo di Manduria-PDO & 0,2025 & 0,0607 & 3,3353 & 0,0009 & $* * *$ \\
\hline Salice Salentino-PDO & 0,0947 & 0,054 & 1,753 & 0,0797 & $*$ \\
\hline Castel del Monte-PDO & 0,2365 & 0,0567 & 4,1691 & $<0,0001$ & $* * *$ \\
\hline Gioia del Colle-PDO & 0,2362 & 0,0644 & 3,6631 & 0,0003 & $* * *$ \\
\hline Locorotondo-PDO & 0,1981 & 0,0769 & 2,5735 & 0,0101 & $* *$ \\
\hline Moscato di Trani-PDO & 0,2047 & 0,1017 & 2,0126 & 0,0443 & $* *$ \\
\hline Colline Joniche Tarantine-PDO & 0,5068 & 0,1276 & 3,9705 & $<0,0001$ & $* * *$ \\
\hline Cacc' e mitte di Lucera-PDO & 0,3954 & 0,1276 & 3,0972 & 0,002 & $* * *$ \\
\hline \multicolumn{6}{|l|}{ Dependent Variable $=\ln$ Price } \\
\hline \multicolumn{3}{|l|}{ F Statistic F $(28,2251)=61,01907$} & \multicolumn{3}{|c|}{ P-value $(F)=1,3 \mathrm{E}-251$} \\
\hline \multicolumn{3}{|l|}{$\mathrm{R}^{2}=0,568074$} & \multicolumn{3}{|c|}{ Adjusted R2 = 0,561457 } \\
\hline \multicolumn{3}{|l|}{ Log-likelihood $=\quad-979,0143$} & \multicolumn{3}{|c|}{ Akaike criterion 2016,029} \\
\hline \multicolumn{3}{|c|}{ Significance: $* * * 1 \% ; * * 5 \% ; * 10 \%$} & \multicolumn{3}{|c|}{ Hannan-Quinn 2076,659 } \\
\hline
\end{tabular}

Among dummies for the categorical variable Variety, only three - Primitivo, International and Minor autochtonous - are statistically significant. In the case of Primitivo and International the coefficients are negative, meaning that consumers are willing to pay less $(-10 \%$ in the first case and $-13 \%$ in the second) in comparison with wines made from blends of grapes, used as baseline. Wines from minor Apulian autochthonous varieties do have a higher value, equal to $15 \%$, all other characteristics being equal.

The last categorical variable, Appellation, which is referred to the area of production, contributes to explain price variability displaying statistical significance for four PGIs and six PDOs. All coefficients of the dummy variables are positive and have to be interpreted as price premium compared to the dummy Other PDOs which has been considered as baseline, all other characteristics being equal. So, PGI Valle d'Itria presents the highest coefficient, meaning that wines with such appellation get a $29 \%$ premium price compared to the baseline appellations, followed by PDO Castel del Monte $(+23 \%)$, PDO Gioia del Colle (23\%), PGI Salento (22\%), PGI Puglia (+21\%), PDO Moscato di Trani (+20\%), PDO Primitivo di Manduria (20\%), PDO Locorotondo (+19\%), PGI Daunia (17\%) and PDO Salice Salentino (9\%).

\section{Conclusions}

Wine is a highly differentiated product and some of the main attributes which affect market competition are defined as search attributes since they can be known prior to purchase. In fact, consumers can easily look for wines that satisfy their own preferences for characteristics as colour, alcohol content, variety, age, area of production and sensory characteristics. The hedonic price model applied to a sample of wines produced in Puglia provided a measure of the market value of these attributes that can be used to investigate some important features of this industry and to provide some insights on the wineries strategies. The study shows that Apulian wines prices evidence a high variability which mainly depends on attributes that can be valued by consumers before the purchase.

A first evidence is the positive influence of alcoholic content on wine price, that has been already found in a study about wines from three Italian regions: Piedmont, Liguria and Valle d'Aosta [13]. It can be explained with the traditional pattern of wine consumption in Italy, but particularly in Southern areas, where alcohol content is still considered an important signal of quality. Moreover, it needs to be outlined that weather conditions of Puglia influence the production of grapes with high sugar content and so high alcoholic strength of wines.

The empirical results about the effect of aging conformed to a priori expectations, as in Costanigro et al. [17], showing that the age of the wine, similarly to the alcoholic content, is an attribute that heavily affects consumers perception of wine quality. However, wine ageing implies higher costs for wineries related to storage and to the delay in selling. 
Organoleptic quality can be known by consumers with reference to the evaluation provided by experts through a scoring system easily readable on guidebooks, magazines, web sites and other media. It has a clear correlation with wine prices since purchasers evidence a willingness to pay more for wines with sensory characteristics objectively judged superior. Findings are consistent with previous researches and suggest that consumers value such information [5, 7, 9, 13, 21, 22, 24, 25, 28, 29].

The role played by the Geographical Indications and the Designations of Origin gives interesting results since significant dummies variables have positive coefficients. Purchasers recognize a premium price to the well known PDO as Castel del Monte, Gioia del Colle, Moscato di Trani, Primitivo di Manduria, Locorotondo andSalice Salentino and it is worth to note that three PGI (Salento, Puglia and Daunia) have a higher influence on price compared to the group Other PDOs, used as baseline. There is evidence that PDO certification, that is at the top of the Italian pyramid of quality, in some cases has less influence on price than PGI certification, characterized by looser roots in the area of origin. Indeed, PDO certification is characterized by more stringent rules about both grapes production and winemaking process and needs proper coordination mechanisms for the collective governing body (the Consortium) jointed to adequate management. On the other hand, the production of PGI wines takes advantage of more flexibility in all production stages, allowing the blending of more varieties and making possible to better react to changes in market trends. For this reason many Apulian producers prefer to use the certification PGI for their top quality production in order to compete in national and international markets. The influence of the region of origin on price has been showed by Schamel [16], Schamel and Anderson [9] and Troncoso [22] and, particularly, some studies showed a strong relationship between Denomination of Origin certification and price [22,30-32]. On the other hand, Nerlove [24] found that the origin of wine has low significant influence on price and Steiner [14] found a low valuation of French wines with geographical appellation in United Kingdom.

The study of the influence of the grape variety on the purchase price does not always lead to similar results according to the literature. Some authors found a sensitivity of the price to varieties, positive or negative depending on variety [23] or just positive [22], while other studies proved a weak correlation [14]. In the present study the estimation model has highlighted the positive influence of the Apulian minor autochthonous varieties on price variability, compared to wines made from blends of varieties. The influence of blends on price is also highlighted by San Martin et al. [23] who, however, refer to blends including Malbec and Cabernet Sauvignon, which are not minor varieties. In the present paper, the price premium associated with wines from minor autochthonous varieties can be related to the feature of such wines to convey a strong identity, both sensory and emotional, clearly opposed to the so-called international style. So, probably, these wines better satisfy the requests from consumers characterized by curiosity, with a medium-high and high level of wine knowledge and oriented to new taste experiences. However, an Italian study about wines from the Italian regions Piedmont, Liguria and Valle d'Aosta evidences different results showing negative coefficients for wines from autochthonous varieties [13]. It is important to take into account that the production of varietal wines from autochthonous grapes requires great investments aimed to varietal conversion and to solve some important technical problems. In fact, they are characterized by low productivity, strongly linked to microclimatic and pedological conditions, and by some critical aspects in oenological process.

Finally, although some limitations in the sample of data provided by the considered guidebook, as the number of only three wines per winery, the results of this study may contribute to understand the Apulian wine market. Further research could be carried out considering a greater number of wines and comparing the benefit associated with a quality attribute (implicit price) with the relative costs incurred.

\section{References}

[1] Ismea 2016

[2] E. Oczkowski, "A Hedonic Price Function for Australian Premium Table Wine", Australian Journal of Agricultural Economics 38(1), 93-110 (1994)

[3] K.J. Lancaster, "A new approach to consumer theory", Journal of Political Economy 74(2), 132157 (1966)

[4] S. Rosen, "Hedonic prices and implicit markets: Product differentiation in pure competition", Journal of Political Economy 82(1), 34-55 (1974)

[5] G. Schamel, "Geography Versus Brands in a Global Wine Market”, Agribusiness 22(3), 363-374 (2006)

[6] D. Hassan, \& S. Monier-Dilhan, National brands and store brands: Competition through public quality labels. Agribusiness 22(1), 21-30 (2006)

[7] S. Lecocq, and M. Visser, "What Determines Wine Prices: Objective vs Sensory Characteristics", Journal of Wine Economics 1(1), 42-56 (2006)

[8] E. Oczkowski, "Hedonic Wine Price Functions and Measurement Error”, The Economic Record 77(239), 374-382 (2001)

[9] G. Schamel and K. Anderson, "Wine Quality and Varietal, Regional and Winery Reputation: Hedonic Prices for Australia and New Zealand", The Economic Record 79(246), 357-369 (2003)

[10] L.A. Panzone and O.M. Simões, “The importance of regional and local origin in the choice of wine: Hedonic models of Portuguese wines in Portugal", Journal of Wine Research 20(1), 27-44 (2009)

[11] S. Landon and C. Smith "Quality Expectations, Reputation, and Price", Southern Economic Journal 64(3), 628-647 (1998)

[12] B. Ling, and L. Lockshin, "Components of wine prices for Australian wine: How winery reputation, wine quality, region, vintage, and winery size contribute to the price of varietal wines", Australasian Marketing Journal 11(3), 19-32 (2003)

[13] P. Pavese and R. Zanola "Autochthon vs. blended wines: Do objective and sensory characteristics matter?" WP n.18, Periodico mensile on-line POLIS Working Papers (2008)

[14] B.E. Steiner "Australian wines in the British wine market: A hedonic price analysis", Agribusiness 20(3), 287-307 (2004) 
[15] D. Carlucci and A. Seccia, "Vini varietali e vitigni autoctoni: evidenze empiriche del mercato italiano", Rivista di Economia Agraria 65(1), 43-62 (2010)

[16] G. Schamel, "Individual and Collective Reputation Indicators of Wine Quality Cies Discussion Paper 0009 (2000)

[17] M. Costanigro, J.J. McCluskey and R.C. Mittelhammer, "Segmenting the wine market based on price: hedonic regression when different prices mean different products", Journal of Agricultural Economics 58(3), 454-466 (2007)

[18] S. Mueller Loose and G. Szolnoki, "Market price differentials for food packaging characteristics", Food Quality and Preference 25(2), 171-182 (2012)

[19] E. Brentari, R, Levaggi and P. Zuccolotto, "Pricing strategies for Italian red wine" Food Quality and Preference 22(8), 725-732 (2011)

[20] A. Coppola, V, Sodano and F. Verneau, "Explaining price variability in the Italian market for high quality wines", Rivista di Economia Agroalimentare 5(1), 127-139 (2000)

[21] J.W. Haeger and K. Storchmann, "Prices of America Pinot Noir wines: climate, craftsmanship, critics", Agricultural economics 35(1), 67-78 (2006)

[22] J.L. Troncoso, and M. Aguirre, "Price determinants of Chilean wines in the U.S. market: a hedonic approach", Spanish Journal of Agricultural Research 4(2), 124-129 (2006)

[23] G. San Martin, J.L. Troncoso and B. Brümmer, "Determinants of Argentinean Wine Prices in the U.S.", Journal of Wine Economics 3(1), 72-84 (2008)
[24] M. Nerlove, "Hedonic price functions and measurement of preferences: the case of Swedish wine consumers", European Economic Review 39(9), 1697-1716 (1995)

[25] P. Combris, S, Lecocq and M. Visser, "Estimation of a hedonic price equation for Bordeaux wine: Does quality matter?", The Economic Journal 107(441), 390-402 (1997)

[26] J.J. Fogarty, "The return to Australian fine wine", European Review of Agricultural Economics 33(4), 542-561 (2006)

[27] O. Ashenfelter, "Predicting the quality and prices of Bordeaux wine", The Economic Journal 118(529), 174-184 (2008)

[28] A. Di Vittorio and V. Ginsburgh, "Pricing Red Wines of Médoc: Vintages from 1949 to 1989 at Christie's auctions". Journal de la Société Statistique de Paris 137 (1995)

[29] T. Lima "Price and Quality in the California Wine Industry: An Empirical Investigation" Journal of Wine Economics 1(1), 176-190 (2006)

[30] L. Benfratello, M. Piacenza, and S. Sacchetto, "Taste or reputation: What drives market prices in the wine industry? Estimation of a hedonic model for Italian premium wines", Appl. Econ. 41(17), 2197-2209 (2009)

[31] C. Chambolle, E. and Giraud-Héraud, "Certification of Origin as a non-tariff barrier", Review of International Economics 13(3), 461-471 (2005)

[32] R. Veale, and P. Quester "Consumer Sensory Evaluations of Wine Quality: The Respective Influence of Price and Country of Origin" Journal of Wine Economics 3(1), 10-29 (2008) 